\title{
SORÇÃO E LIXIVIAÇÃO DE TIAMETOXAM EM SOLOS TRATADOS COM LODO DE ESGOTO E CULTIVADOS COM CAFEEIRO
}

Ciro Augusto de Souza Magalhães*

Empresa Brasileira de Pesquisa Agropecuária - Embrapa Roraima, Rod. BR-174, km 8, 69301-970 Boa Vista - RR, Brasil

José Maria de Lima, Alisson Lucrécio da Costa, Evânia Geralda da Silva e Carlos Alberto Silva

Departamento de Ciência do Solo, Universidade Federal de Lavras, CP 3037, 37200-000 Lavras - MG, Brasil

Wagner Bettiol

Empresa Brasileira de Pesquisa Agropecuária - Embrapa Meio Ambiente, CP 69, 13820-000 Jaguariúna - SP, Brasil

Julio Cesar Azevedo Nóbrega

Universidade Federal do Piauí, Campus Universitário Ministro Petrônio Portella, 64049-550 Teresina - PI, Brasil

Paulo Tácito Gontijo Guimarães

Empresa de Pesquisa Agropecuária de Minas Gerais, Centro Tecnológico do Sul de Minas, Campus da Universidade Federal de Lavras, 37200-000 Lavras - MG, Brasil

Recebido em 14/2/11; aceito em 22/11/11; publicado na web em 23/1/12

\begin{abstract}
SORPTION AND LEACHING OF THIAMETHOXAM IN SOILS TREATED WITH SEWAGE SLUDGE AND CULTIVATED WITH Coffee arabica. The objective of this study was to evaluate the sorption and leaching of thiamethoxam in dystrophic RedYellow Latosol (LVAd), dystroferric Red Latosol (LVdf) and Red-Yellow Argisol (PVAd) with coffee under the effect of sewage sludge doses. There was thiamethoxam sorption decreasing at higher doses of sewage sludge in LVAd and LVdf. In the PVAd, sorption was higher in samples that received the highest dose of sewage sludge. At 150 days after the application of thiamethoxam, the compound began to be detected in the effluent, in all soils. Dissolved organic carbon had no influence on the thiamethoxam leaching.
\end{abstract}

Keywords: biosolid; pesticides contamination; dissolved organic carbon.

\section{INTRODUÇÃO}

A utilização do lodo de esgoto na agricultura tem como principal benefício a incorporação de nutrientes ao solo. ${ }^{1}$ Porém, alguns efeitos indesejáveis de sua aplicação no solo são objetos de muitos estudos, o que tem resultado em normas restritivas para seu aproveitamento na agricultura. Altas concentrações de micronutrientes e metais pesados são a principal razão dessas restrições. ${ }^{2} \mathrm{~A}$ aplicação de lodo de esgoto no solo resulta também no aumento do teor de matéria orgânica, ${ }^{3}$ o que é um efeito positivo, devido à sua influência positiva sobre atributos físicos do solo. ${ }^{4}$

Em relação aos atributos físicos, existem relatos de que a aplicação de lodo de esgoto promove aumento na porosidade total e macroporosidade, ${ }^{5}$ diminuição na densidade do solo ${ }^{6}$ e aumento da retenção de água em solos arenosos. ${ }^{7}$ A matéria orgânica tem efeitos indiretos no solo, por melhorar a agregação e aumentar a porosidade. ${ }^{8}$ Assim, é de se esperar que em solos que recebam altas doses de resíduos orgânicos a infiltração de água seja maior, o que pode facilitar o transporte de agrotóxicos no perfil do solo, notadamente aqueles mais solúveis em água.

O inseticida tiametoxam é um desses produtos; pertence à classe dos neonicotinoides e foi introduzido no Brasil para o controle de pragas em várias culturas, especialmente no cafeeiro. Sua aplicação no solo controla insetos-praga da parte aérea, como é o caso do bicho-mineiro em folhas de cafeeiro. O uso desse inseticida nas lavouras cafeeiras vem aumentando rapidamente; com isso, aumenta-se o risco de contaminação de água subterrânea, pois sua molécula é polar (log Kow $=-0,165)$, com baixa retenção pelas partículas do solo. ${ }^{9}$

A sorção do tiametoxam constitui, principalmente, processo de partição do composto entre a solução aquosa e a matéria orgânica do

*e-mail: ciro@cpafrr.embrapa.br solo. ${ }^{10} \mathrm{~A}$ aplicação de lodo de esgoto no solo aumenta a quantidade de carbono, que pode ser dividido em frações solúveis e insolúveis em água. Se, por um lado, a fração orgânica insolúvel aumenta a sorção de agrotóxicos, a fração orgânica dissolvida pode reduzir a sorção, devido às interações entre as moléculas de agrotóxicos e a matéria orgânica dissolvida, ou pode dificultar a interação das moléculas do composto com as moléculas de água, por reduzir a afinidade entre essas moléculas, influenciando a solvatação do produto. ${ }^{10} \mathrm{~A}$ competição pelos sítios de sorção no solo também afeta a sorção do agrotóxico. ${ }^{11}$ Parte dele pode se movimentar no solo ao se associar à matéria orgânica dissolvida., ${ }^{9,12}$ Entretanto, dependendo das características das camadas mais profundas do solo, essa parte que se movimenta poderá interagir com a fase mineral, ficando o produto retido no solo, como, por exemplo, no caso de camadas mais oxídicas. ${ }^{10} \mathrm{O}$ balanço final dessas reações depende, ainda, da interação da matéria orgânica proveniente do lodo de esgoto com a fase mineral do solo, dependendo, portanto, do tipo de solo. ${ }^{13}$

As informações são ainda incipientes a respeito da sorção de agrotóxicos em solos tropicais que receberam resíduos orgânicos, como lodo de esgoto. Sabe-se que são resíduos mais estabilizados, que sofreram transformações químicas ao longo do processo de tratamento do esgoto e que podem ter efeitos desconhecidos no solo quanto à sorção de moléculas orgânicas. A qualidade da matéria orgânica pode influenciar nesse processo, já que a fração argila de solos intemperizados, por conter altos teores de óxidos e hidróxidos de ferro e alumínio, pode se ligar à fração orgânica e assim reduzir a sorção de agrotóxicos, aumentando o risco de lixiviação e contaminação de fontes de água. ${ }^{10}$

Diferenças entre solos, como sua mineralogia, textura e estrutura, além da composição química do lodo de esgoto e da própria molécula do agrotóxico devem ser consideradas, bem como a possibilidade de práticas de manejo e preparo do solo que podem contribuir para 
aumentar os riscos de contaminação do meio ambiente. Objetivou-se, neste trabalho, avaliar a sorção e a lixiviação de tiametoxam em solos cultivados com cafeeiro, sob efeito de doses de lodo de esgoto, em colunas de lisímetros contendo amostras indeformadas de dois Latossolos e um Argissolo da região de Lavras, MG.

\section{PARTE EXPERIMENTAL}

O experimento foi instalado na Bateria de Lisímetros do Departamento de Ciência do Solo da Universidade Federal de Lavras (UFLA). No local, foi instalada uma estação meteorológica automática, para registrar dados de precipitação pluvial e temperatura do ar, dentre outros. Esses elementos climáticos são apresentados na Figura 1, além da percolação média nas colunas, para o período de condução do experimento (maio a dezembro de 2010).

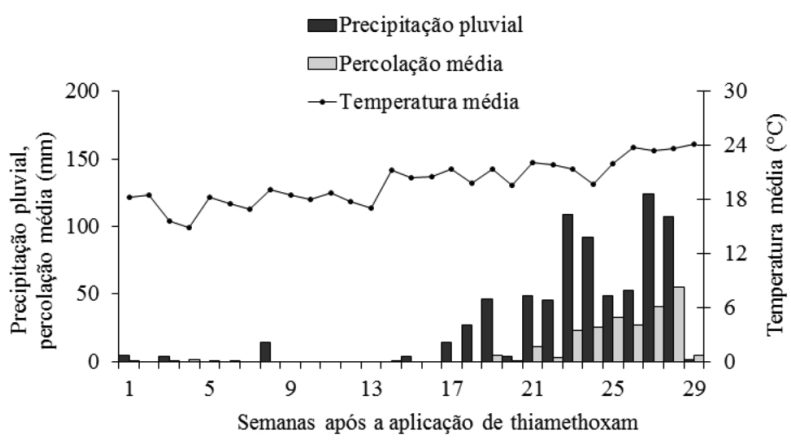

Figura 1. Precipitação pluvial, temperatura média e percolação média semanais durante a condução do experimento

Foram utilizadas colunas de $0,9 \mathrm{~m}$ de profundidade e $1,0 \mathrm{~m}$ de diâmetro, contendo material com estrutura original de três solos de ocorrência na região de Lavras, Minas Gerais (Latossolo Vermelho distroférrico - LVdf, Latossolo Vermelho-Amarelo distrófico - LVAd e Argissolo Vermelho-Amarelo distrófico - PVAd).

Antes da aplicação do lodo de esgoto, foram coletadas amostras de solo na camada de $0-20 \mathrm{~cm}$ e do horizonte B diagnóstico para a realização de análises físicas e químicas (Tabela 1). ${ }^{14}$ Baseada nos resultados da análise química (Tabela 1), foi realizada calagem (em 8/4/2009) e fosfatagem corretiva (em 15/5/2009), em todos os lisímetros. A quantidade de calcário foi calculada pelo método de saturação por bases, para elevá-la a $70 \%$. Assim, as quantidades adicionadas de calcário (36\% de $\mathrm{CaO} ; 14 \%$ de $\mathrm{MgO}$ e PRNT igual a 95\%) foram 1,6; 2,6 e 5,7 $\mathrm{Mg} \mathrm{ha}^{-1}$ (megagramas por hectare ou toneladas por hectare) para o LVAd, LVdf e PVAd, respectivamente. Já a quantidade de fósforo adicionada correspondeu a $2000 \mathrm{~kg} \mathrm{ha}^{-1}$ de $\mathrm{P}_{2} \mathrm{O}_{5}$, via superfosfato simples, em todos os solos (essa quantidade foi elevada, em função da recomendação de $80 \mathrm{~g}$ de $\mathrm{P}_{2} \mathrm{O}_{5}$ na cova de plantio de cada muda de cafeeiro).

O delineamento experimental foi o de blocos casualizados, em esquema fatorial 3 (solos) x 4 (doses de lodo de esgoto: 0, 11, $22 \mathrm{e}$ $44 \mathrm{Mg} \mathrm{ha}^{-1}$, identificadas como D0, D1, D2 e D3, respectivamente, e aplicadas 7 meses antes da implantação da cultura do café, e 0, 8, 16 e $32 \mathrm{Mg} \mathrm{ha}^{-1}$ aplicadas 4 meses após o transplantio das mudas), com três repetições. Na primeira aplicação, o lodo de esgoto foi colocado em área total e incorporado até $20 \mathrm{~cm}$ de profundidade, em 15/5/2009. Também, na segunda aplicação, em 16/4/2010, o lodo foi distribuído em área total e incorporado até $20 \mathrm{~cm}$ de profundidade, evitando-se o revolvimento do solo abaixo da projeção da copa das mudas de café.

Cerca de 2 meses após a primeira aplicação de lodo de esgoto, foi cultivado feijoeiro, que foi colhido no final de outubro de 2009. No
Tabela 1. Granulometria, óxidos do ataque sulfúrico e índices de intemperismo da camada de 0-20 cm e do horizonte diagnóstico dos solos utilizados no experimento

\begin{tabular}{|c|c|c|c|c|c|c|c|c|}
\hline \multirow{2}{*}{ Solo } & \multirow{2}{*}{ Areia } & Silte & Argila & $\mathrm{SiO}_{2}$ & $\mathrm{Al}_{2} \mathrm{O}_{3}$ & \multirow{2}{*}{$\mathrm{Fe}_{2} \mathrm{O}_{3}$} & \multirow{2}{*}{$\mathrm{Ki}^{*}$} & \multirow{2}{*}{$\mathrm{Kr}^{* *}$} \\
\hline & & \multicolumn{4}{|c|}{$\mathrm{g} \mathrm{kg}^{-1}$} & & & \\
\hline & \multicolumn{8}{|c|}{$0-20 \mathrm{~cm}$} \\
\hline LVAd & 360 & 48 & 592 & 171 & 233 & 82 & 1,25 & 1,04 \\
\hline LVdf & 232 & 91 & 677 & 167 & 268 & 263 & 1,06 & 0,65 \\
\hline \multirow[t]{2}{*}{ PVAd } & 467 & 203 & 330 & 195 & 175 & 59 & 1,89 & 1,56 \\
\hline & \multicolumn{8}{|c|}{ Horizonte B diagnóstico } \\
\hline LVAd & 320 & 48 & 632 & 197 & 270 & 95 & 1,24 & 1,01 \\
\hline LVdf & 146 & 93 & 760 & 169 & 274 & 285 & 1,05 & 0,63 \\
\hline PVAd & 307 & 177 & 516 & 238 & 247 & 76 & 1,64 & 1,37 \\
\hline
\end{tabular}

* Ki: $1,7\left(\% \mathrm{SiO}_{2}\right) /\left(\% \mathrm{Al}_{2} \mathrm{O}_{3}\right) ; * * \mathrm{Kr}: 1,7\left(\% \mathrm{SiO}_{2}\right) /\left[\% \mathrm{Al}_{2} \mathrm{O}_{3}+0,64\left(\% \mathrm{Fe}_{2} \mathrm{O}_{3}\right)\right]$

final de novembro de 2009, foi iniciado o cultivo do milho e, aproximadamente 30 dias após a semeadura, foi realizado o transplantio de duas mudas de café "Mundo Novo 379/19", entre as linhas de milho existentes em cada lisímetro. Cerca de 1 mês após a colheita das espigas de milho e o corte dos tocos das plantas de milho nos lisímetros, foi reaplicado o lodo de esgoto nas doses já citadas, para avaliar seu potencial em fornecer nutrientes para a cultura do café. Cerca de 10 dias após a reaplicação do lodo de esgoto, uma muda de café foi retirada, deixando-se a muda que apresentava melhor desenvolvimento.

O lodo de esgoto utilizado no experimento é originário da estação de tratamento de esgotos em Jundiaí, São Paulo, onde esgotos predominantemente domésticos são tratados. Esse material passou por um processo de compostagem, com aproximadamente 100 dias de duração e apresenta teores de $\mathrm{N}=22,3 ; \mathrm{P}=4,0 ; \mathrm{K}=4,0 ; \mathrm{Ca}=$ 23,$4 ; \mathrm{Mg}=1,9 ; \mathrm{S}=6,2 ; \mathrm{Na}=2,0$ e $\mathrm{Fe}=11,1 \mathrm{~g} \mathrm{~kg}^{-1} ; \mathrm{B}=4,3 ; \mathrm{Cu}=$ 175; $\mathrm{Mn}=247$ e $\mathrm{Zn}=1285 \mathrm{mg} \mathrm{kg}{ }^{-1}$, com relação $\mathrm{C} / \mathrm{N}=16 .{ }^{15} \mathrm{No}$ início de maio de 2010, amostras de solo foram retiradas em cada lisímetro, para os ensaios de sorção de tiametoxam nos solos. Nessa mesma época, o tiametoxam foi aplicado nos lisímetros, na dose de $125 \mathrm{mg}$ de ingrediente ativo por planta, diluídos em $50 \mathrm{~mL}$ de água.

Para o ensaio de sorção, o método utilizado foi em batelada (batch). Tubos de vidro com $8,5 \mathrm{~cm}$ de comprimento, $2,0 \mathrm{~cm}$ de diâmetro e $20 \mathrm{~mL}$ receberam $3 \mathrm{~g}$ de solo (TFSA) e $10 \mathrm{~mL}$ de solução de $\mathrm{CaCl}_{2}$ 0,01M contendo tiametoxam nas concentrações 0,$1 ; 0,5 ; 1,0$; 5,0 e $10,0 \mu \mathrm{g} \mathrm{mL}^{-1}$; os ensaios foram feitos em duplicata. Os tubos foram agitados durante $4 \mathrm{~h}$; em seguida, foram centrifugados a 710 $\mathrm{g}$, por $30 \mathrm{~min}$. Foi retirada uma alíquota de $1,5 \mathrm{~mL}$ do sobrenadante, filtrada em membrana de 0,45 m (PTFE) e armazenada em câmara fria $\left(5^{\circ} \mathrm{C}\right)$ para posterior análise por cromatografia líquida de alta eficiência (CLAE). A concentração de tiametoxam sorvida ao solo foi calculada pela diferença entre a concentração inicial e a concentração do composto na fase aquosa, após a agitação e centrifugação, multiplicada pelo volume de solução e dividida pela massa de solo.

Os recipientes de coleta de água do efluente das colunas foram regularmente verificados para a quantificação do volume percolado e amostragem, para posterior análise em CLAE. Relacionando-se a concentração de tiametoxam na amostra de água do efluente com o volume percolado, obteve-se a quantidade lixiviada, em relação ao total aplicado. Foi determinada também a concentração de carbono orgânico dissolvido nas amostras de água percoladas, em um analisador de carbono, marca Elementar modelo Vario TOC Cube.

Para determinação quantitativa do tiametoxam, foi utilizado um sistema de CLAE, HP 1100, operando com detector de ultravioleta, com comprimento de onda de $255 \mathrm{~nm}$. A coluna utilizada foi 
Waters Spherisorb ODS-2, $5 \mu \mathrm{m}, 150$ x 3,2 mm. A fase móvel foi acetonitrila/água milli-Q, na proporção 20/80, com fluxo de $0,3 \mathrm{~mL}$ $\min ^{-1}$ e volume de injeção de $100 \mu \mathrm{L}$. Nessas condições, o tempo de retenção do tiametoxam ficou em torno de 8,2 min. A quantificação da concentração do tiametoxam foi realizada por comparação da área dos picos das amostras com a curva padrão de calibração. O limite de detecção do tiametoxam foi de $0,03 \mathrm{mg} \mathrm{L}^{-1}$.

Os resultados de sorção foram analisados com relação à sua adequação à isoterma de Freundlich (Equação 1), onde:

$$
S=K_{f} C_{e}^{1 / n}
$$

em que: $S$ é a concentração de equilíbrio do agrotóxico na fase sólida do solo $\left(\mathrm{mg} \mathrm{kg}^{-1}\right) ; K_{f}$ é a constante de Freundlich $\left[\left(\mathrm{mg} \mathrm{kg}^{-1}\right)\right.$ $\left.\left(\mathrm{L} \mathrm{mg}^{-1}\right)^{1 / n}\right] ; C_{e}$ é a concentração de equilíbrio em solução $\left(\mathrm{mg} \mathrm{L}^{-1}\right) \mathrm{e}$ $1 / n$ é a constante que expressa a linearidade da equação. ${ }^{16}$

Os coeficientes de Freundlich para sorção e dessorção, teor de carbono orgânico no solo e dissolvido na água percolada pelas colunas e as quantidades de tiametoxam lixiviadas foram submetidos à análise de variância e as médias comparadas pelo teste de Scott-Knott, a 5\% de probabilidade.

\section{RESULTADOS E DISCUSSÃO}

Os resultados obtidos para a sorção do tiametoxam ajustaram-se à Equação de Freundlich (Tabela 2), com os coeficientes de determinação $\left(\mathrm{r}^{2}\right)$ variando de 0,95 a 0,99 . A sorção, quando comparada entre os três solos na ausência de lodo de esgoto (D0), foi maior no LVdf, fato atribuído ao maior teor de matéria orgânica desse solo, na condição D0 (de acordo com os dados da Tabela 2). A influência direta da mineralogia na sorção de tiametoxam já foi estudada anteriormente. A sorção de tiametoxam em hematita, goethita sintética e caulinita, minerais comuns de serem encontrados em solos tropicais, é negligenciável. ${ }^{10}$

A matéria orgânica é a responsável pela retenção de agrotóxicos em solos, ${ }^{10,17,18}$ porém a interação das partículas minerais do solo com a fração orgânica pode interferir na disponibilização de sítios de carga das moléculas orgânicas, reduzindo a afinidade dessas moléculas pelos agrotóxicos no solo. ${ }^{10}$ Nos Latossolos, a interação do lodo de esgoto com os minerais predominantes (óxidos de ferro e alumínio) resultou, num primeiro momento, em aumento da sorção de tiametoxam. Entretanto, na presença de grande quantidade de lodo incorporado ao solo (D3), a sorção do composto foi reduzida sobremaneira, principalmente no LVdf, que apresentou $\mathrm{K}_{\mathrm{f}}$ menor que na condição D0. Já no Argissolo, a aplicação de lodo de esgoto afetou positiva e significativamente a sorção, resultando em maiores valores de $\mathrm{K}_{\mathrm{f}}$ na dose D3. Nos Latossolos, que são solos mais intemperizados, com maiores teores de óxidos de ferro e alumínio e, consequentemente, apresentam menores valores de $\mathrm{Ki}$ e $\mathrm{Kr}$ ( $\mathrm{Ta}-$ bela 1), parte da matéria orgânica adicionada interagiu com esses óxidos, neutralizando sítios de carga negativa na matéria orgânica e positiva na superfície dos óxidos. Assim, essa interação entre os compostos orgânicos (em maiores quantidade em D2 e D3) e minerais resultou em menor retenção do composto, por isso a menor sorção nas maiores doses de lodo de esgoto. Por outro lado, no PVAd os teores de óxidos de ferro e alumínio são menores, diminuindo essa forma de neutralização da matéria orgânica, permitindo uma maior sorção de tiametoxam nesse compartimento, nas maiores doses de lodo de esgoto. Os coeficientes de sorção do tiametoxam obtidos, especialmente nos Latossolos que receberam altas doses de lodo de esgoto e no Argissolo, na ausência de lodo de esgoto, indicam alta disponibilidade do composto na solução do solo em condições de campo. Isso é vantajoso em termos de absorção pelo sistema radicular
Tabela 2. Matéria orgânica do solo (MOS), constante de Freundlich $\left(K_{f}\right)$, coeficiente de linearidade $(1 / n)$ e coeficiente de determinação $\left(\mathrm{r}^{2}\right)$ para a sorção de tiametoxam em amostras da camada superficial $(0-20 \mathrm{~cm})$ de Latossolo Vermelho-Amarelo distrófico (LVAd), Latossolo Vermelho distroférrico (LVdf) e Argissolo Vermelho-Amarelo distrófico (PVAd) tratados com lodo de esgoto e cultivados com cafeeiro

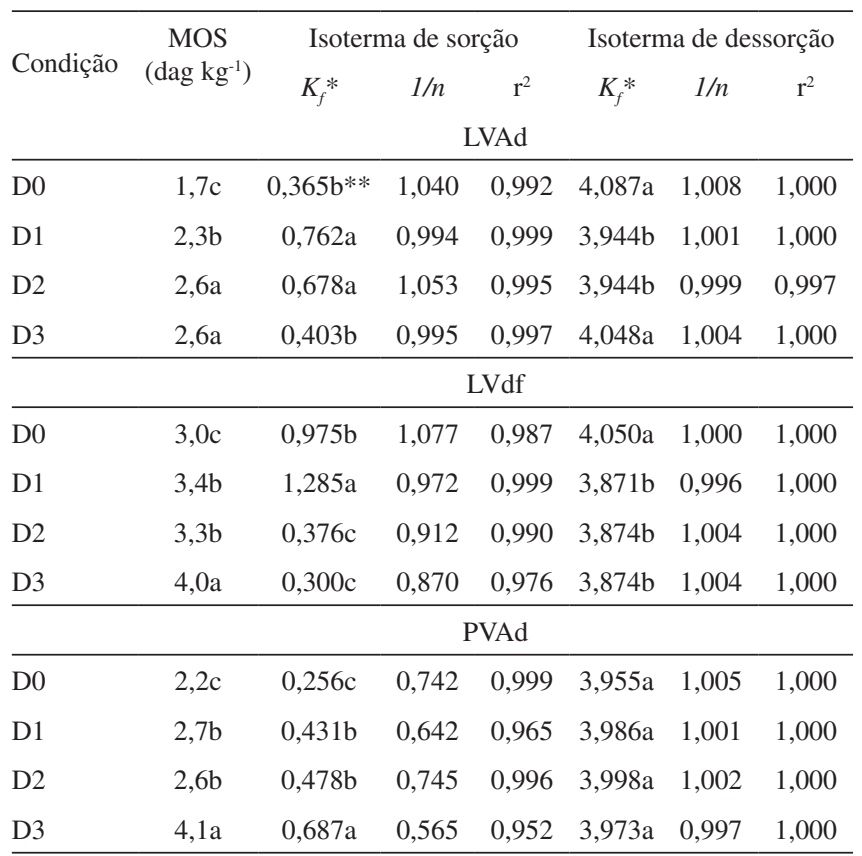

$* \mathrm{~K}_{\mathrm{f}}\left(\mathrm{mg}^{1-1 / \mathrm{n}} \mathrm{L}^{1 / \mathrm{n}} \mathrm{kg}^{-1}\right)$; ** Médias seguidas pela mesma letra nas colunas, para cada solo, não diferem entre si pelo teste de Scott-Knott, a 5\% de probabilidade.

e, consequentemente, maior controle contra o inseto-praga, mas, por outro lado, a ocorrência de chuvas intensas poderá resultar em elevada lixiviação do inseticida nesses solos.

Os valores do parâmetro $1 / n$ (Tabela 2) para a sorção apresentaram comportamento diferenciado para os solos. Nos Latossolos, esses valores foram mais próximos de 1, e no PVAd eles foram menores, principalmente nas doses mais elevadas de lodo, indicando a diminuição da disponibilidade de sítios de sorção em maiores concentrações de tiametoxam na solução, o que reflete em maior potencial de lixiviação, caso ocorram volumes significativos de chuvas pouco tempo depois da aplicação do produto.

As isotermas de dessorção também se ajustaram ao modelo de Freundlich, com valores de $\mathrm{r}^{2}$, a maioria, iguais a 1 . Os baixos valores de concentração inicial e, consequentemente, na concentração de equilíbrio durante a sorção representam menor dificuldade no ajuste do modelo, comparativamente aos dados de sorção; isso explica os altos valores de $\mathrm{r}^{2}$. Além disso, os valores de $K_{f}$ foram muito maiores para a dessorção, indicando que uma vez sorvido, o composto dificilmente retorna à solução do solo, fenômeno conhecido como histerese, de ocorrência comum na sorção desses compostos em solo, em função de diferentes forças envolvidas no processo de sorção e dessorção no solo. ${ }^{19}$

Na Figura 2 são apresentadas as quantidades lixiviadas de tiametoxam em função dos solos e das doses de lodo de esgoto. Os dados são apresentados apenas a partir do início da estação chuvosa na região de Lavras, MG, já que, anteriormente, não houve precipitação suficiente para a ocorrência de percolação profunda. Para o LVAd, as quantidades lixiviadas seguiram o comportamento previsto em relação ao encontrado para a sorção, ou seja, maior lixiviação sob as maiores doses de lodo de esgoto. Já, no LVdf, a maior lixiviação de tiametoxam ocorreu justamente na condição D1, apesar dessa condi- 
ção ter proporcionado o maior coeficiente de sorção $\left(\mathrm{K}_{\mathrm{f}}\right)$. A lixiviação de tiametoxam nas outras condições não diferiu significativamente. No PVAd houve maior quantidade lixiviada na condição D2, sem diferenças entre as demais doses. Com base nos resultados obtidos, pode-se afirmar que a lixiviação de tiametoxam, principalmente no LVAd e PVAd, parece ter sido influenciada pelo lodo de esgoto, mas de forma indireta, pela melhoria da infiltração de água. ${ }^{8}$ Como a molécula do tiametoxam apresenta alta solubilidade em água $(4,1$ $\mathrm{g} \mathrm{L}^{-1}$ ), é mais provável que, independentemente do comportamento sortivo demonstrado em condições de equilíbrio (ensaios de sorção e dessorção realizados em laboratório), a lixiviação do composto no perfil de solo é influenciada principalmente pela mineralogia, textura e estrutura do solo, que interferem no tempo de contato entre a fase líquida e sólida do solo, em condições de lâminas elevadas de precipitação. Em condições de laboratório, depois de atingido o equilíbrio, é possível definir o comportamento sortivo do tiametoxam nesses solos. Porém, em condições de campo (ou próximo disso - em lisímetros), a passagem da água pelo solo (infiltração) leva consigo íons e outras substâncias químicas que estão presentes na superfície das partículas do solo (superfície dos macroporos, que é por onde ocorre a drenagem interna de água no solo). Isso faz com que a análise de sorção não represente fielmente o comportamento ambiental do tiametoxam, devido à grande variabilidade dos atributos que afetam a condutividade hidráulica do solo. ${ }^{20,21}$
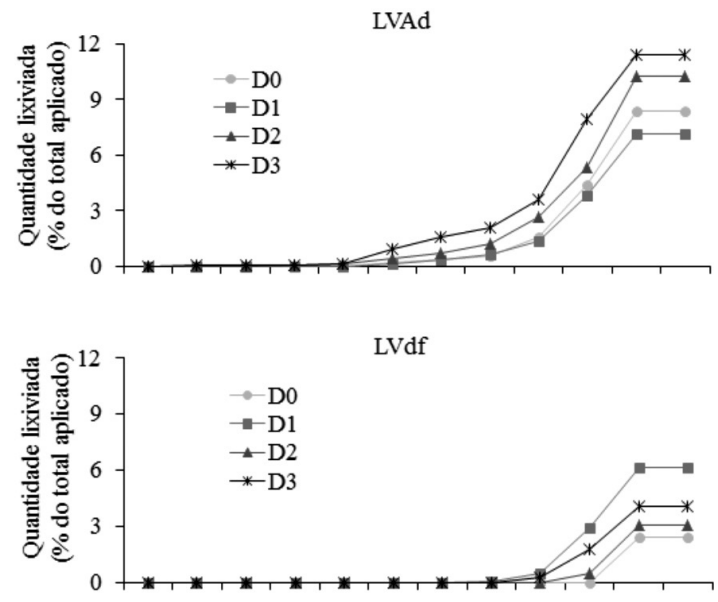

PVAd

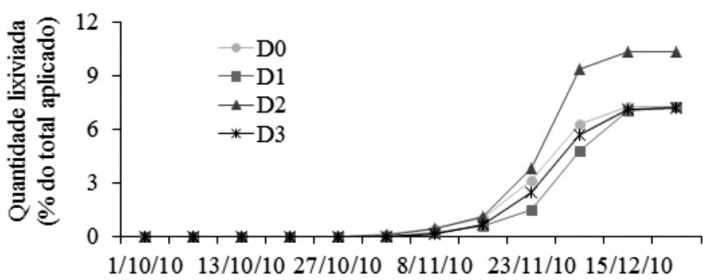

Figura 2. Quantidade acumulada de tiametoxam no efluente de solos cultivados com café e tratados com lodo de esgoto. LVAd: Latossolo Vermelho-Amarelo distrófico; LVdf: Latossolo Vermelho distroférrico; PVAd: Argissolo Vermelho-Amarelo distrófico

Em relação aos solos, a lixiviação de tiametoxam foi mais pronunciada justamente nos solos com menores teores de óxidos de ferro (LVAd e PVAd). Nesses solos, a lixiviação média, no período avaliado, foi, respectivamente, 9,3 e 8,0\% do total aplicado, enquanto no LVdf esse valor foi de $3,9 \%$. O LVdf é o solo que apresenta maior teor de óxidos e de argila, o que o destaca como um grande filtro ambiental, retendo potenciais poluentes de águas subterrâneas. ${ }^{20}$
As concentrações de carbono orgânico dissolvido (COD) (Figura 3) não diferiram no LVdf e LVAd, apesar do aumento da quantidade de lodo de esgoto aplicada, e estiveram próximas de $10 \mathrm{mg} \mathrm{L}^{-1}$. Já no PVAd, ocorreu um incremento do COD nas maiores doses de lodo, alcançando valores superiores a $30 \mathrm{mg} \mathrm{L}^{-1}$ de efluente das colunas. Esse comportamento é reflexo da mineralogia dos solos, pois os Latossolos apresentam maior teor de óxidos e hidróxidos de ferro e alumínio, o que faz com que as moléculas orgânicas com carga negativa sejam retidas ao longo do perfil do solo, onde ocorre um aumento da concentração desses óxidos, sendo que, nas condições de $\mathrm{pH}$ dos solos agrícolas, exibem cargas de superfície positiva (cargas dependentes de $\mathrm{pH}){ }^{22}$

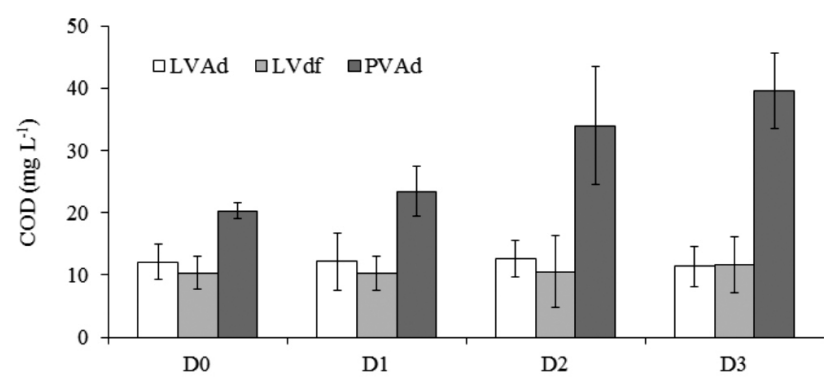

Figura 3. Concentração de carbono orgânico dissolvido (COD, média de 5 amostragens, com linhas de desvio padrão, $C V=24,0 \%)$ no efluente de solos cultivados com café e tratados com lodo de esgoto. LVAd: Latossolo Vermelho-Amarelo distrófico; LVdf: Latossolo Vermelho distroférrico; PVAd: Argissolo Vermelho-Amarelo distrófico

Na Figura 4 é apresentada a concentração de carbono orgânico dissolvido (COD) versus a concentração de tiametoxam. Não houve correlação significativa em nenhum dos três solos, o que descarta a possibilidade do COD ser responsável pelo transporte de tiametoxam no perfil do solo. Para os Latossolos, essa constatação já era esperada, por não terem ocorrido diferenças entre as concentrações de COD. Porém, no PVAd, a concentração de COD aumentou com o acréscimo das doses de lodo aplicadas, mas sua correlação com a concentração de tiametoxam não foi significativa. Como a molécula do tiametoxam apresenta alta polaridade, sua afinidade com os vários compostos orgânicos que percolaram pelas colunas não foi expressiva, de modo a provocar alguma influência na lixiviação do tiametoxam em condições próximas às encontradas naturalmente.

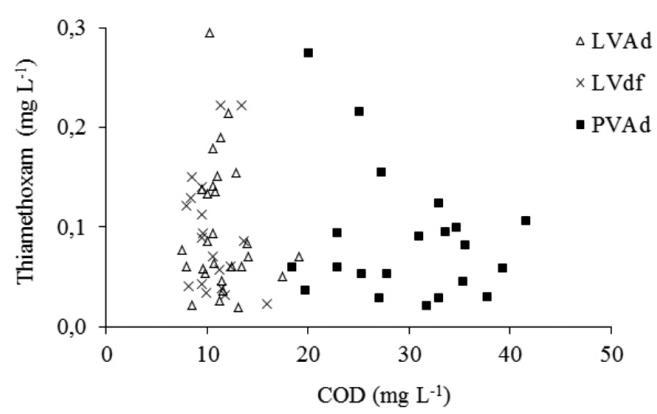

Figura 4. Concentração de carbono orgânico dissolvido (COD) e de tiametoxam em amostras de água percolada de lisímetros, sob efeito de doses de lodo de esgoto. LVAd: Latossolo Vermelho-Amarelo distrófico; LVdf: Latossolo Vermelho distroférrico; PVAd: Argissolo Vermelho-Amarelo distrófico

O tiametoxam é conhecido como um composto que apresenta alta mobilidade no solo. ${ }^{9}$ Essa mobilidade pode ser maior ainda em solos com histórico de uso de lodo de esgoto. Assim, o emprego de ambos, tiametoxam e lodo de esgoto compostado, deve ser feito com conhe- 
cimento técnico e bom senso. Devem ser tomados maiores cuidados no uso de lodo e tiametoxam nos solos de menor profundidade, de teores reduzidos de óxidos de ferro e alumínio, no caso do Latossolo Vermelho-Amarelo e do Argissolo Vermelho-Amarelo estudado.

\section{CONCLUSÕES}

A adição de altas doses de lodo de esgoto compostado diminui a sorção de tiametoxam nos Latossolos avaliados, porém, no Argissolo Vermelho-Amarelo distrófico, a sorção de tiametoxam aumenta em função das doses de lodo de esgoto compostado.

Em condições próximas às condições naturais (colunas de lisímetros), a lixiviação das moléculas de tiametoxam é influenciada principalmente por fatores que interferem na condutividade hidráulica do solo, o que provoca maior ou menor tempo de contato das moléculas do composto com as partículas do solo.

Os teores de carbono orgânico dissolvido aumentaram em função das doses de lodo de esgoto somente no Argissolo Vermelho-Amarelo distrófico e não se correlacionaram com a concentração de tiametoxam no efluente das colunas.

\section{AGRADECIMENTOS}

À FAPEMIG, CAPES, CNPq, EPAMIG e INCT/CAFÉ, por bolsas de estudos e de pesquisa concedidas, apoio financeiro e suporte logístico, aos Drs. F. C. Oliveira e J. J. Chiaradia (Biossolo Agricultura e Ambiente Ltda.) e à Opersan Serviços Ambientais, pelo fornecimento do lodo de esgoto.

\section{REFERÊNCIAS}

1. Bettiol, W.; Camargo, O. A., eds.; Lodo de esgoto: impactos ambientais na agricultura, Embrapa Meio Ambiente: Jaguariúna, 2000, cap. 2.

2. Kabata-Pendias, A.; Pendias, H.; Trace elements in soils and plants, $3^{\text {rd }}$ ed., CRC Press: Boca Raton, 2001.

3. Ricci, A. B.; Padovani, V. C. R.; Paula Júnior, D. R.; Rev. Bras. Cienc. Solo 2010, 34, 543.
4. Melo, W. J.; Marques, M. O.; Santiago, G.; Chelli, R. A.; Leite, S. A. S.; Rev. Bras. Cienc. Solo 1994, 18, 449.

5. Pagliai, M.; Guidi, G.; La Marca, M.; Giachetti, M.; Lucamante, G.; J. Environ. Qual. 1981, 10, 556

6. Aggelides, S.M.; Londra, P. A.; Bioresour. Technol. 2000, 71, 253.

7. Debosz, K.; Petersen, S. O.; Kure, L. K.; Ambus, P.; Appl. Soil Ecol. 2002, 19, 237

8. Metzger, L.; Yaron, B.; Adv. Soil Sci. 1987, 7, 141.

9. Castro, N. R. A.; Tese de Doutorado, Universidade Federal de Lavras, Brasil, 2005.

10. Urzedo, A. P. F. M.; Rigitano, R. L. O.; Lima, J. M.; Castro, N. R. A.; Pesticidas: Rev. Ecotoxicol. Meio Amb. 2006, 16, 71.

11. Briceño, G.; Palma, G.; Duran, N.; Crit. Rev. Environ. Sci. Technol. 2007, 37, 233.

12. Cells, R.; Barriuso, E.; Houot, S.; J. Environ. Qual. 1998, 27, 1348.

13. Inda Júnior, A. V.; Bayer, C.; Conceição, P. C.; Boeni, M.; Salton, J. C.; Tonin, A. T.; Cienc. Rural 2007, 37, 1301.

14. EMBRAPA; Manual de métodos de análise de solo, $2^{\mathrm{a}}$ ed., Embrapa Solos: Rio de Janeiro, 1997.

15. Higashikawa, F. S.; Silva, C. A.; Bettiol, W.; Rev. Bras. Cienc. Solo 2010, 34, 1743.

16. Green, R. E.; Karickhoff, S. W. Em Pesticides in the soil environment: processes, impacts and modeling; Cheng, H. H., ed.; SSSA: Madison, 1990, cap. 4.

17. Briggs, G. G.; J. Agric. Food Chem. 1981, 29, 1050.

18. Chiou, C. T. Em Humic substances in soil and crop sciences: selected readings; Maccarthy, P.; Clapp, C. E.; Malcolm, R. L.; Bloom, P. R., eds.; ASA/SSSA: Madison, 1990, p. 111-149.

19. Fernandes, M. C.; Cox, L.; Hermosín, M. C.; Cornejo, J.; Pest Manage. Sci. 2006, 62, 1207.

20. Resende, M.; Curi, N.; Rezende, S. B.; Corrêa, G. F.; Pedologia: base para distinção de ambientes, $3^{\mathrm{a}}$ ed., NEPUT: Viçosa, 1999.

21. Mesquita, M. G. F. B.; Moraes, S. O.; Cienc. Rural 2003, 34, 963.

22. Goldberg, S.; Davis, J. A.; Hem, J. D. Em The environmental chemistry of aluminum; Sposito, G., ed.; CRC Press, Lewis Publ.: Boca Raton, 1996, p. 271-331. 